\title{
A technique to detect psychogenic sensory loss
}

\author{
RICHARD TEGNER \\ From the Department of Neurology, Karolinska Hospital, Stockholm, Sweden
}

SUMMARY Tactile thresholds were measured in six patients with psychogenic hypaesthesia using a forced choice procedure. The response to stimuli close to threshold differed in a characteristic manner from that seen in patients with peripheral or central nervous system damage.

Psychogenic sensory deficits can be detected by forced choice testing. ${ }^{1}$ A patient who claims he cannot perceive a certain stimulus is asked to "guess" whether it is present or not; significantly fewer correct responses are obtained than expected from the binomial distribution. This paper describes an alternative method. It is a modified version of a previously described and validated procedure to measure tactile thresholds in organic diseases. ${ }^{2}$

\section{Patients and methods}

The study comprised two men and four women aged 23-47 years. They all presented with typical psychogenic weakness of the dominant upper extremity. ${ }^{34}$ In addition they had hypaesthesia of non-anatomical distribution. To test for light touch calibrated von Frey hairs were used. Each patient was first tested on the normal homologue area and this was again examined at the end of the experimental session to exclude a failure of general attention. A short pretest indicated the appropriate stimulus strengths to be used in further testing. Patients were told they would hear a sound and then either be touched by a hair or not, which they should report as "yes" or "no". Testing comprised a random series of blocks, within each of which the same von Frey hair was used for 10 stimuli randomly interspersed with 10 null stimuli. A total of 40 trials were made with each von Frey hair and on each side. From observed frequencies of "yes" responses on stimuli ("hits") and on null stimuli ("false alarms"), A' was calculated. This is a measure of sensitivity which is independent of patient's response criterion ${ }^{25}$ (such as, how eager the subject is to make a hit or how reluctant he is to make a false alarm).

Address for reprint requests: Richard Tegnér, Department of Neurology, Karolinska Hospital, Box 60 500, S-104 01, Stockholm, Sweden.

Received 8 April 1988 and in revised form 21 June 1988. Accepted 1 July 1988

\section{Results}

Up to now more than 40 patients with unilateral peripheral or central sensory disturbances of known aetiology have been examined with this technique. A typical stimulus-response relationship in tactile hypaesthesia from a traumatic nerve injury is shown in the figure. There is a rightward shift on the hypaesthetic side and $A^{\prime}$ increases monotonously with increasing stimulus strength up to $A^{\prime}=1$ which is $100 \%$ correct responses.

This contrasts with psychogenic hypaesthesia (see figure) where $A^{\prime}$ did not change with increasing stimulus strength but instead varied randomly around a mean value that would correspond to about $10-30 \%$ correct "yes" responses (provided that there were no false alarms). The false alarm rate was in all six patients and at all stimulus strengths below $5 \%$ with no significant differences.

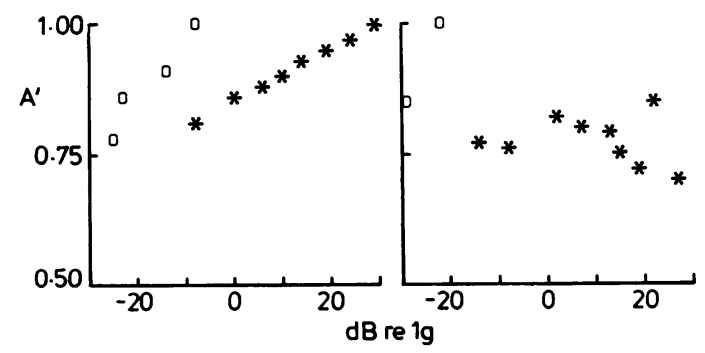

Fig Tactile sensitivity measured with von Frey hairs in traumatic radial nerve injury (left) and in psychogenic hypaesthesia (right). Stimulus intensity is expressed in decibels with $1 \mathrm{~g}$ as reference.

Normal side $O$, abnormal side*. 


\section{Discussion}

Traditionally, psychogenic sensory deficits are diagnosed by their variability, by a sharp transition at the midline, and by a non-anatomical distribution. ${ }^{467}$ This has been disputed by Gould et al who found "typical" hysterical features in $70 \%$ of patients with acute CNS damage. ${ }^{8}$ The type of variability described in the present study has never been observed by the author in peripheral or central nerve damage, including parietal lobe lesions, and does not seem to be compatible with organic origin.

According to the theory of signal detection, the response criterion value is assessed by the false alarm rate. ${ }^{2}$ It is noteworthy that all patients with psychogenic hypaesthesia had low, stable false alarm rates, which would indicate strict response criteria.

Using the present technique, all patients cooperated fully. In contrast, three of the patients who were asked to guess whether a stimulus they previously had claimed they did not feel, was present or not (see above) refused to participate; it is reasonable to assume that they had seen through its purpose. A similar observation was made by Miller:9 a patient with hysterical sensory loss had evidently understood the aim of the examination and consequently used some algorithm so that he could respond at about chance level despite the large number of trials. Only by splitting up the responses into blocks and comparing observed and expected frequencies of correct responses with a $\chi^{2}$ test was it possible to reveal the non organic nature of the sensory loss. Such a more complicated analysis was not necessary in the present study but could be applied to the data since the trials were run in blocks.

Many laboratories now use automated systems to measure sensory thresholds. ${ }^{10}$ They are mostly based on two-alternative forced choice techniques. " These procedures are useful for examining patients with known organic diseases, for example, to measure the severity of diabetic polyneuropathy. They are, however, less useful for differential diagnosis since they will not reveal psychogenic sensory disturbances. This is true of all present methods that specify the sensory threshold as a single value.

This work was supported by MS-fonden.

\section{References}

1 Grosz HJ, Zimmerman J. Experimental analysis of hysterical blindness. Arch Gen Psychiatry 1965;13: 256-60.

2 Sekuler R, Nash D, Armstrong R. Sensitive, objective procedure for evaluating response to light touch. Neurology 1973;23:1282-91.

3 Worden RE, Johnson EW, Burk RD. Diagnosis of hysterical paralysis. Arch Phys Med Rehab 1961;42: 122-3.

4 Green MA. Neurological manifestations of conversion hysteria. Trans Am Neurol Assoc 1955;86:196-8.

5 Pollack I, Norman DA. A non-parametric analysis of recognition experiments. Psychon Sci 1964;1:125-6.

6 Weiser HI. Motor sensory dysfunction of the upper limb due to conversion syndrome. Arch Phys Med Rehab 1976;57:17-9.

7 Lightburn JL, Cattell RB, Stephenson WF. Differential diagnosis of conversion reactions in a general hospital. Postgrad Med 1958;23:140-7.

8 Gould R, Miller BL, Goldberg MA, Benson DF. The validity of hysterical signs and symptoms. J Nerv Ment Dis 1986;174:593-7.

9 Miller E. Detecting hysterical sensory symptoms: An elaboration of the forced choice technique. Br J Clin Psychol 1986;25:231-2.

10 Dyck PJ, Zimmerman IR, O'Brien PC, et al. Introduction of automated systems to evaluate touch-pressure, vibration, and thermal cutaneous sensation in man. Ann Neurol 1978;4:502-10.

11 Wetherill GB, Chen G, Vasudeva RB. Sequential estimation of quantal response curves: a new method of estimation. Biometrika 1966;53:439-54. 